\title{
Visceral Artery Aneurysms and Pseudoaneurysms: Retrospective Analysis of Interventional Endovascular Therapy of $\mathbf{4 3}$ Aneurysms
}

\section{Aneurysmen und Pseudoaneurysmen viszeraler Arterien: Retrospektive Analyse der interventionellen radiologischen Therapie von $\mathbf{4 3}$ Aneurysmen}

Authors

Hannes Ruhnke, Thomas J. Kröncke

\section{Affiliation}

Department of Diagnostic and Interventional Radiology and Neuroradiology, Klinikum Augsburg, Germany

Key words

visceral artery aneurysm, visceral artery pseudoaneurysm, acute bleeding, endovascular therapy

received 25.10.2016

accepted 08.03.2017

\section{Bibliography}

DOI http://dx.doi.org/10.1055/s-0043-107239

Published online: 16.5.2017 | Fortschr Röntgenstr 2017; 189: 632-639 @ Georg Thieme Verlag KG Stuttgart · New York

ISSN 1438-9029

Correspondence

Dr. Hannes Ruhnke

Department of Diagnostic and Interventional Radiology and

Neuroradiology, Klinikum Augsburg

Stenglinstraße 2

86156 Augsburg

Germany

Tel.: ++ 49/8 21/4002441

hannes.ruhnke@gmx.de

\section{ABSTRACT}

Purpose To evaluate the results of interventional endovascular therapy of incidental and symptomatic visceral artery aneurysms in the elective and emergency situation.

Materials and Methods 43 aneurysms in 38 patients ( 19 female, 19 male, mean age: $57 \pm 16$ years [18 - 82]) were treated between 2011 and 2015. The characteristics of the aneurysms (true vs. false aneurysm, size, etiology, location, symptoms) were considered. Furthermore, we evaluated the intervention with respect to technical success, embolic/occlusive agents used, therapy-associated complications and postinterventional follow-up.

Results 23 true aneurysms (maximum diameter: $22 \pm 18 \mathrm{~mm}$ [11-67 mm]) and 20 false aneurysms (maximum diameter:
$9 \pm 33 \mathrm{~mm}[3-150 \mathrm{~mm}])$ were evaluated. The splenic $(n=14)$ and renal arteries $(n=18)$ were most frequently affected. The etiology was most commonly degenerative-atherosclerotic (47\%) or iatrogenic post-operative (19\%). 18/48 interventions were performed due to active bleeding. False aneurysms were associated significantly more often with active bleeding (63 vs. $25 \%, p=0.012$ ). 41/48 treatments were technically successful. Re-intervention was necessary 6 times. In 2 cases the endovascular approach did not succeed. There was a complication rate of $10 \%$, whereby only 4 minor and 1 major complications occurred. No patient suffered from permanent sequelae. Aneurysms were primarily treated by using coils and if necessary additional embolic agents (liquid embolic agent or vascular plugs) (75\%). In the follow-up period, reperfusion of treated aneurysms occurred at a rate of $7 \%(n=3)$.

Conclusion Interventional endovascular therapy of visceral artery aneurysms is safe and effective in the elective treatment of incidental aneurysms as well as in significantly more frequent hemorrhaging false aneurysms in the emergency situation.

\section{Key points}

- Interventional endovascular therapy of visceral artery aneurysms is safe and effective.

- In more than $60 \%$ of cases visceral artery pseudoaneurysms are associated significantly more often with a history of bleeding or acute bleeding. Hence, there is a need for (interventional) therapy even in small pseudoaneurysms.

- Follow-up seems to be useful to detect reperfusion as manifestation of treatment failure.

\section{Citation Format}

- Ruhnke H, Kröncke T], . Visceral Artery Aneurysms and Pseudoaneurysms: Retrospective Analysis of Interventional Endovascular Therapy of 43 Aneurysms. Fortschr Röntgenstr 2017; 189: 632-639

\section{ZUSAMMENFASSUNG}

Ziel Evaluation der Erfahrungen in der interventionellen endovaskulären Therapie von inzidentellen und symptoma- 
tischen Aneurysmen der viszeralen Gefäße in der elektiven sowie der Notfallsituation.

Material und Methoden Zwischen 2011 und 2015 wurden 43 Aneurysmen von 38 Patienten (19 weiblich, 19 männlich, mittleres Alter 57,27 $\pm 16,13$ Jahre [18 - 82]) in 48 Interventionen behandelt. Betrachtet wurden die Charakteristika der Aneurysmen (echtes vs. Pseudoaneurysma, Größe, Genese, Lokalisation, Blutungsstatus, Symptomatik), die Intervention selbst hinsichtlich technischem Erfolg, verwendeten Materialien und interventionsassoziierten Komplikationen sowie die postinterventionelle Nachsorge.

Ergebnisse Behandelt wurden 23 echte Aneurysmen (max. Durchmesser $22 \pm 18 \mathrm{~mm}$ [11-67 mm]) sowie 20 Pseudoaneurysmen (max. Durchmesser $9 \pm 33 \mathrm{~mm}$ [3-150 mm]). Am häufigsten wurde die A. lienalis $(n=14)$ sowie die A. renalis dextra et sinistra $(n=18)$ behandelt. Die Genese war am häufigsten atherosklerotisch (47\%) oder iatrogen postoperativ (19\%). 18/48 Interventionen erfolgten aufgrund einer aktiven oder stattgehabten Blutung, Pseudoaneurysmen waren signifikant häufiger aktiv blutend ( 63 vs. $25 \%, p=0,012$ ). Eine tendenzielle, jedoch nicht signifikante Differenz ergab sich hinsichtlich der Symptomatik zugunsten der Pseudoaneurysmen ( 55 vs. $39 \%, p=0,424)$. 41/48 Behandlungen ( $85 \%$ ) waren primär technisch erfolgreich, 6 Mal war eine Re-Intervention erfolgreich, zweimal gelang der endovaskuläre Zugang nicht. Die Behandlung wies eine Komplikationsrate von $10 \%(n=5)$ auf, in 4 Fällen eine Minor-, in 1 Fall eine Majorkomplikation. Kein Patient litt postinterventionell an dauerhaften therapiebedingten Folgeschäden. Vornehmlich wurden die Aneurysmen mithilfe von Coils und ggf. zusätzlichen Embolisaten (Flüssigembolisat, Vascular Plug) (36/48, $75 \%$ ) versorgt. Im Nachbeobachtungszeitraum zeigte sich eine Reperfusionsrate von $7 \%(n=3)$.

Schlussfolgerung Die interventionelle endovaskuläre Behandlung von Aneurysmen der viszeralen Arterien ist ein sicheres und erfolgreiches Verfahren. Dies gilt sowohl für die elektive Versorgung inzidenteller Aneurysmen als auch für die Therapie signifikant häufiger blutender Pseudoaneurysmen in der Notfallsituation.

\section{Introduction}

Visceral artery aneurysms (VAAs) and pseudoaneurysms are rare vascular pathologies with an average prevalence of $1 \%$ (0.1 $10 \%$ ) [1]. Visceral artery aneurysms are usually asymptomatic and are therefore incidental findings during CT or MRI examination. However, they can be life-threatening in the case of rupture and require urgent intervention. VAAs can be treated by surgery or intervention depending on the location, configuration, comorbidities, and acute clinical condition of the patient. Particularly in the case of extensive comorbidities, endovascular therapy is preferred [2].

This retrospective study analyzes the interventional therapy of (pseudo-) aneurysms of the visceral artery including the branches of the renal artery over a period of 5 years from 2011 to 2015 . Special attention is paid to technical success, periprocedural morbidity, and possible differences between true and false aneurysms.

\section{Materials and Methods}

VAAs were initially identified by searching our radiological information system for the term "aneurysm". Most of the 1187 hits related to cerebral pathologies. Aneurysms of the thoracic and abdominal aorta, the pelvic vasculature, and the popliteal artery were also excluded from further analysis. In total, 48 interventions in 38 patients for the treatment of VAAs were identified. All (pseudo-) aneurysms of the celiac trunk, the superior and inferior mesenteric artery, the splenic artery, and the renal artery were included. True aneurysms were differentiated from pseudoaneurysms based on clinical and visible morphological criteria. Postoperative, post-traumatic, and inflammatory vasodilation was evaluated as pseudoaneurysm based on the pathogenesis. In con- trast, aneurysms in the case of vasculitis and tuberous sclerosis, as well as degenerative aneurysms caused by atherosclerosis were classified as true aneurysms. If an aneurysm was detected and its etiology in connection with a lack of other etiological factors, a suitable patient age and further atherosclerotic vascular changes, could not be otherwise categorized, it was classified as a degenerative aneurysm caused by atherosclerosis.

Data regarding patient age and gender, the number of aneurysms per patient, and the treatment frequency were evaluated. The aneurysm size and any previous or active bleeding were documented. The etiology of the treated aneurysms was differentiated according to aneurysm location. Any associated symptoms were recorded.

Treatments were grouped as interventions performed during regular hours and interventions performed outside of regular hours. The two treatment groups were compared with respect to success rate and periprocedural morbidity. The materials and techniques used in all interventions were evaluated. The percentage of successful primary interventions and the rate of re-interventions were determined. Technical success was defined as the elimination of aneurysmal vascular segments or the afferent/ efferent vessel with verifiable loss of perfusion of the (pseudo-) aneurysm after intervention.

Complications defined as changes directly associated with the intervention occurring within a maximum of 30 days after the intervention were also evaluated. Complications were categorized as minor and major on the basis of the classification of the Society of Interventional Radiology [3].

The type and duration of follow-up and the corresponding treatment success in the post-therapeutic course were documented. Data was collected from digitally archived patient data including medical reports, radiology reports, and laboratory results. 
Interventions were performed by 6 interventional radiologists, all with many years of experience with the endovascular therapy of aneurysms.

Statistical comparison of differences in frequency between two groups was performed using the chi-square test for nominal variables, and feature comparisons between independent groups without normal distribution were performed via U-test. A significance level of $p=0.05$ was defined.

\section{Results}

In total, 38 patients in whom 48 interventions were performed were included in the study. The average age of the 19 women and 19 men was $57.2 \pm 16.1$ years ( $18-82$ years). One patient was treated three times and eight patients were treated two times. 43 aneurysms were treated. Five patients had two aneurysms. There were 23 true aneurysms and 20 pseudoaneurysms including false aneurysms. The aneurysms had a median maximum diameter of $22 \pm 26 \mathrm{~mm}$ (mean: $28 \mathrm{~mm}$, range: $3-150 \mathrm{~mm}$ ). The true aneurysms had a median maximum diameter of $22 \pm 18 \mathrm{~mm}$ (mean: $30 \mathrm{~mm}$, range: $11-67 \mathrm{~mm}$ ). The pseudoaneurysms were significantly smaller with a maximum diameter of $9 \pm 33 \mathrm{~mm}$ (mean: $25 \mathrm{~mm}$, range: $3-150 \mathrm{~mm})(\mathrm{p}=0.04) .42 \%(18 / 43)$ of the VAAs presented with active or prior bleeding at the time of treatment. Pseudoaneurysms were associated with prior or active bleeding significantly more frequently than true aneurysms (63\% vs. $25 \%, p=0.012$ ) ( Table 1 ). The true aneurysms with prior or active bleeding were significantly larger than those without bleeding (median $60 \pm 18 \mathrm{~mm}$ vs. median $20 \pm 7 \mathrm{~mm}, \mathrm{p}=0.004$ ). In contrast, the pseudoaneurysms with bleeding were significantly smaller than those without bleeding (median $6 \pm 11 \mathrm{~mm}$ vs. 30 $\pm 42 \mathrm{~mm}, \mathrm{p}=0.002$ ). This difference equalized over all aneurysms (median: $27 \pm 27 \mathrm{~mm}$ vs. $25 \pm 33 \mathrm{~mm}, \mathrm{p}=0.2$ ). 20 of the 43 treated aneurysms were symptomatic. $39 \%(9 / 23)$ of the true aneurysms presented with clinical symptoms and $55 \%(11 / 20)$ of the pseudoaneurysms with associated symptoms were treated. Abdominal pain was the main symptom in $65 \%(n=13)$ of cases, a relevant drop in $\mathrm{Hb}$ during active bleeding was seen in $20 \%$ $(n=4)$ of cases and gross hematuria was seen in $15 \%(n=3)$ of cases. The symptoms were not caused by active or prior bleeding in 2 cases but rather were a result of the space-occupying effect of the aneurysm.

Aneurysms were treated twice in six cases: as part of repeat treatment in three cases and to treat reperfusion of the already treated aneurysm in three cases.

The splenic artery $(n=14)$ and the renal artery or its parenchymal branches $(n=17)$ were affected most frequently followed by the proper and common hepatic artery $(n=5)$ and the gastroduodenal artery $(n=4)$. The celiac trunk $(n=1)$ and the left and right gastric artery $(n=2)$ were rarely affected $(\triangleright$ Table 2 , - Fig. 1).

The most common etiology of treated aneurysms was degeneration caused by atherosclerosis ( $n=20,47 \%)$. Two aneurysms ( $5 \%$ ) were caused by vasculitis. One aneurysm resulting from tuberous sclerosis (2\%) was treated. A further common cause was a preceding operation $(n=8,19 \%)$, i. e., aneurysm in the renal
- Table 1 Patient characteristics.

englisch patient and aneurysm related variables patients [n]

median age [years]

mean age [years]

aneurysm/pseudoaneurysm [n]

prior or active bleeding

- aneurysms (percentage)

- pseudoaneurysms (percentage)

median maximum diameter [mm]

mean maximum diameter $[\mathrm{mm}]$

aneurysm [mm]

- median

- mean

pseudoaneurysm [mm]

- median

- mean

follow-up period [months]

- mean
- median
38:19 female, 19 male

$57 \pm 16(18-82)$

59

$23 / 20$

18

$6 / 23(25)$

$12 / 20(63)$

$22 \pm 26(3-150)$

28

$22 \pm 18(11-67)$

30

$9 \pm 33(3-150)$

25

$4 \pm 7.2(1-36)$

6.4 artery after partial kidney resection except for in one case (hepatic artery). 7 aneurysms (16\%) were caused by inflammation, usually as part of acute or chronic pancreatitis. The inflammation was not due to pancreatitis per se in only one case. In this case, the inflammation was caused by the leakage of pancreatic juice after a Whipple procedure with pancreaticoduodenal anastomosis insufficiency. 5 aneurysms (12\%) were caused by trauma. > Table 3 shows the etiology of the true aneurysms and pseudoaneurysms.

39 of 48 interventions were performed during regular hours (8:00 am to 5:00 pm) and 9 procedures were performed during on-call times outside of regular hours. $25 \%$ (12/48) of the interventions were performed under endotracheal anesthesia. Interventional therapy of the aneurysms was typically performed via fiber-coated coils $(62.5 \%, n=30)$, combined in individual cases with a stent graft $(8.3 \%, n=4)$, endovascular occluder (vascular plug) $(6.3 \%, n=3)$ or liquid embolic agent $(6.3 \%, n=3)$. A stent graft $(8.3 \%, n=4)$ or a liquid embolic agent $(6.3 \%, n=3)$ was rarely used alone ( $\triangleright$ Fig. 2,3 ). In a few cases particularly when using coils, additional temporary vascular occlusion via Gelfoam was performed when minor residual perfusion of the distal vascular territory was present following coiling. Gelfoam was applied at the implanted coils, and blood stasis was promoted by the thrombogenic properties of the material. - Table 4 provides a precise differentiation of the materials used as a function of the treated vascular territory.

41 primary treatments were technically successful (85.4\%); re-intervention was necessary in 5 cases; and an endovascular approach, and thus interventional therapy, was not successful in 2 cases. Failure of primary treatment was registered in one case. 
- Table 2 Location of treated aneurysms and pseudoaneurysms.

\begin{tabular}{|l|c|c|c|}
\hline location & $\begin{array}{l}\text { frequency [n] } \\
\text { (percentage) }\end{array}$ & aneurysm [n] & pseudoaneurysm [n] \\
\hline right or left renal artery & $17(40)$ & 7 & 10 \\
\hline splenic artery & $14(32)$ & 10 & 4 \\
\hline common and proper hepatic artery & $5(12)$ & 3 & 2 \\
\hline gastroduodenal artery & $4(9)$ & 1 & 3 \\
\hline celiac trunk & $1(2)$ & 1 & 1 \\
\hline left gastric artery & $1(2)$ & 0 & 0 \\
\hline right gastric artery & $1(2)$ & 1 & 0 \\
\hline
\end{tabular}

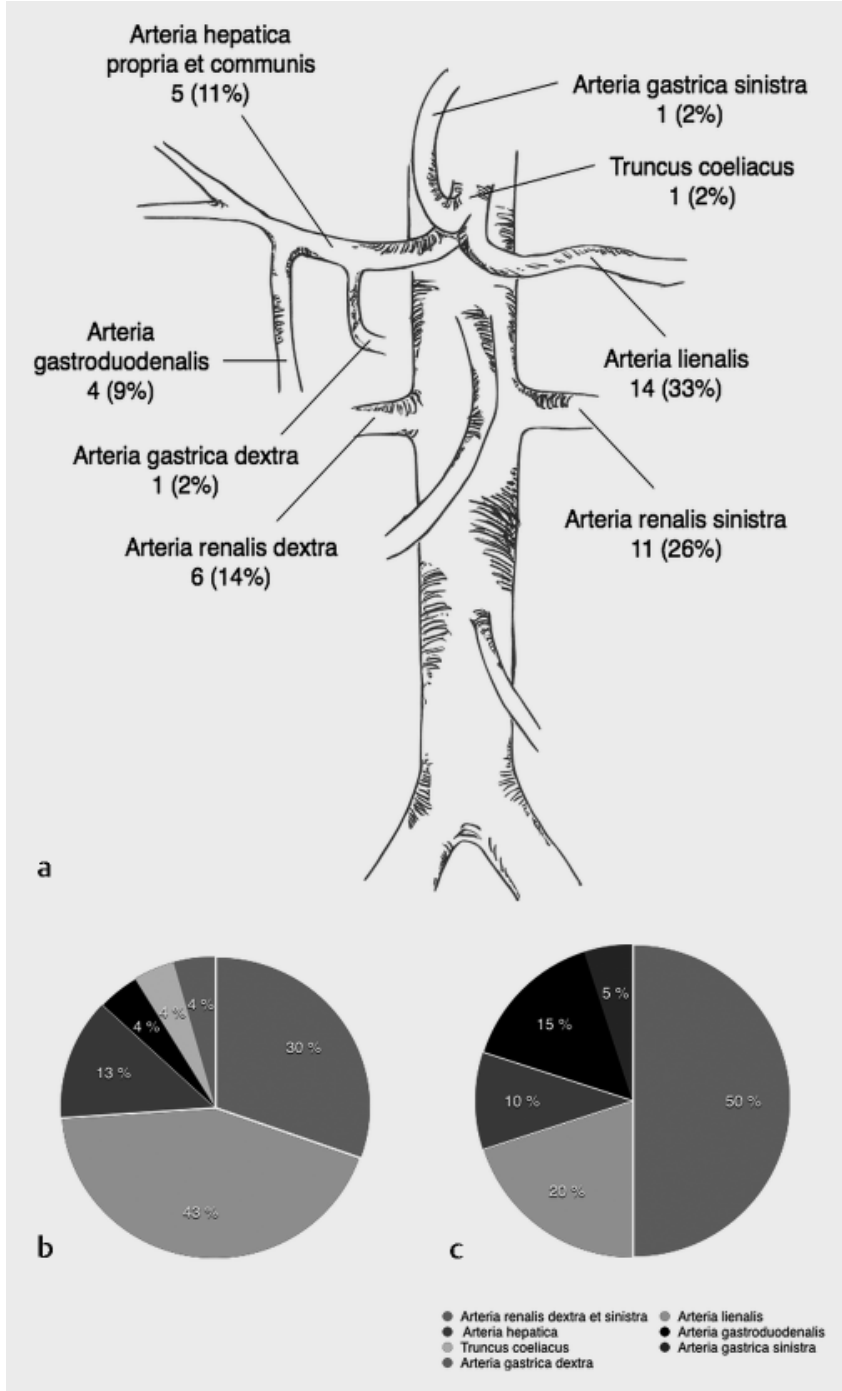

- Fig. 1 Location and incidence of true and false visceral artery aneurysms. A Overview of frequency and distribution of all treated true aneurysms and false aneurysms. B Frequency and distribution of treated true aneurysms. C Frequency and distribution of treated false aneurysms.
- Table 3 Etiology of treated aneurysms and pseudoaneurysms.

\begin{tabular}{|l|c|c|}
\hline etiology & $\begin{array}{l}\text { frequency [n] } \\
\text { (percentage) }\end{array}$ & $\begin{array}{l}\text { aneurysm/ } \\
\text { pseudoaneurysm }\end{array}$ \\
\hline atherosclerosis & $20(47)$ & \multirow{2}{*}{ aneurysm } \\
\hline vasculitis & $2(5)$ & \\
\hline tuberous sclerosis & $1(2)$ & \multirow{2}{*}{ pseudoaneurysm } \\
\hline \begin{tabular}{l|l|} 
postoperative \\
iatrogenic
\end{tabular} & $8(19)$ & \\
\hline inflammation & $7(16)$ & \\
\hline trauma & $5(12)$ & \\
\hline
\end{tabular}

Due to complex anatomical conditions, the intervention had to be aborted without occlusion of the actively bleeding pseudoaneurysm of the renal artery. The patient had to subsequently undergo surgical nephrectomy. In the second case the celiac trunk was not able to be successfully treated via a transbrachial approach. The intervention was terminated and the aneurysm was treated in a second session via a transfemoral approach.

The complication rate for all endovascular interventions was $10.4 \%(n=5)$. There were 4 minor complications and 1 major complication according to the SIR classification (Society of Interventional Radiology) [3]. The complications included 4 parenchymal infarctions in the flow region of the treated aneurysms. These were all partial splenic infarctions ( $\bullet$ Fig. 4). A loss of spleen function was not observed in any of the patients in the follow-up period. They only experienced abdominal pain caused by post-embolization syndrome. Liver infarction or intestinal ischemia was not seen. The only major complication was temporary incomplete ischemia of the arm and the formation of a cubital abscess after a transbrachial approach to treat an aneurysm of the celiac trunk. The ischemia was quickly resolved with post-interventional intravenous heparinization. The abscess was opened surgically and healed without complications. There was no increase in the complication rate with respect to aneurysms with prior or active bleeding treated in the emergency situation compared to incidental aneurysms treated on an elective basis. There was a trend toward increased periprocedural morbidity with respect to treat- 

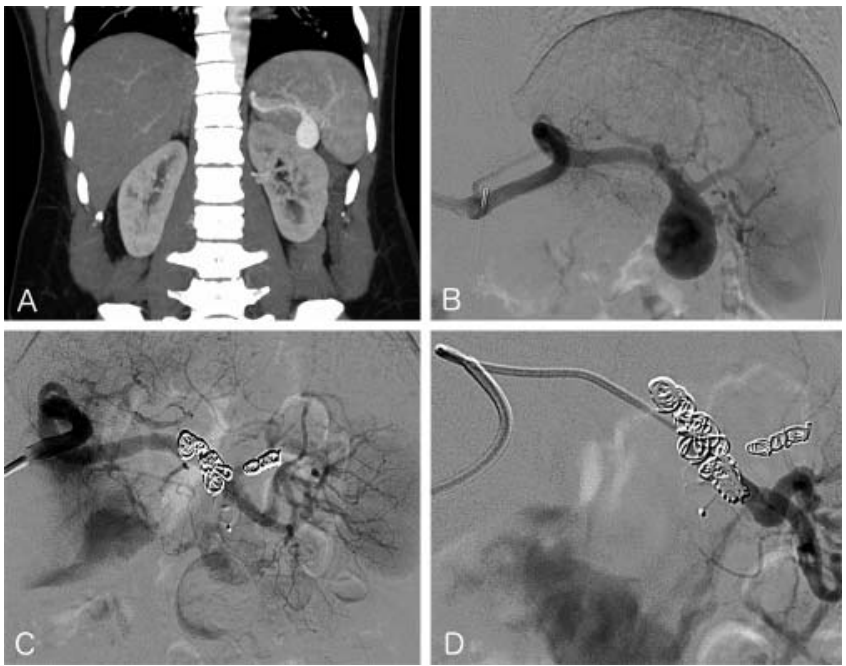

- Fig. 2 Case example of a true aneurysm of the splenic artery. A Computed tomography (coronal formatted MIP) of an incidental sacciform aneurysm of the splenic artery in a 46-year-old female patient. B Same aneurysm as in A in selective angiography with faint demarcation of overlying segmental arteries. C After coiling and additional implantation of a vascular plug initially incomplete closure of aneurysm neck with persisting contrasting of aneurysm lumen. D Postinterventional situation in DSA after successful embolization in a second session. Complete closure after additional coil implantation in the aneurysm neck.

ment outside of regular hours that was, however, not statistically significant (22\% (2/9) vs. $8 \%(3 / 39), p=0.265)$. Only splenic infarctions resulting in extended hospitalization in only one case occurred here.

None of the patients suffered from lasting damage caused by the intervention and none of the patients died during their hospital stay following interventional therapy.

Follow-up varied greatly. $62.5 \%(n=30)$ of all interventions were followed-up at the hospital. The median period for followup using diagnostic imaging was $4 \pm 7.2$ months (mean: 6.4, range: 1 - 36 months). In 6 cases only immediate post-interventional success control during inpatient care or up to 30 days after treatment was performed. Follow-up was performed via computed tomography in most cases $(60 \%, n=18)$, via contrast-enhanced ultrasound (CEUS) and supplementary CT in 4 cases, exclusively via CEUS ( $\triangleright$ Fig. 5 ) in 2 cases and via B-mode ultrasound, CEUS, EUS (endosonography), and MRI in one case each. In 3 cases, the treated aneurysm was controlled by a combination of MRI and conventional angiography. 3 of the 43 aneurysms had to be treated again after 2 weeks, 2 months, and 4 months, respectively, due to the detection of reperfusion. This yields a reperfusion rate of $7 \%$ in the follow-up period. The 8 implanted stent grafts had a patency rate of $100 \%$ in the median follow-up period of 3.5 months (average: 3.75 , range: $0-8$ months).

\section{Discussion}

The goal of this study was to examine the endovascular therapy of visceral arteries at the Augsburg Hospital over a period of 5 years.
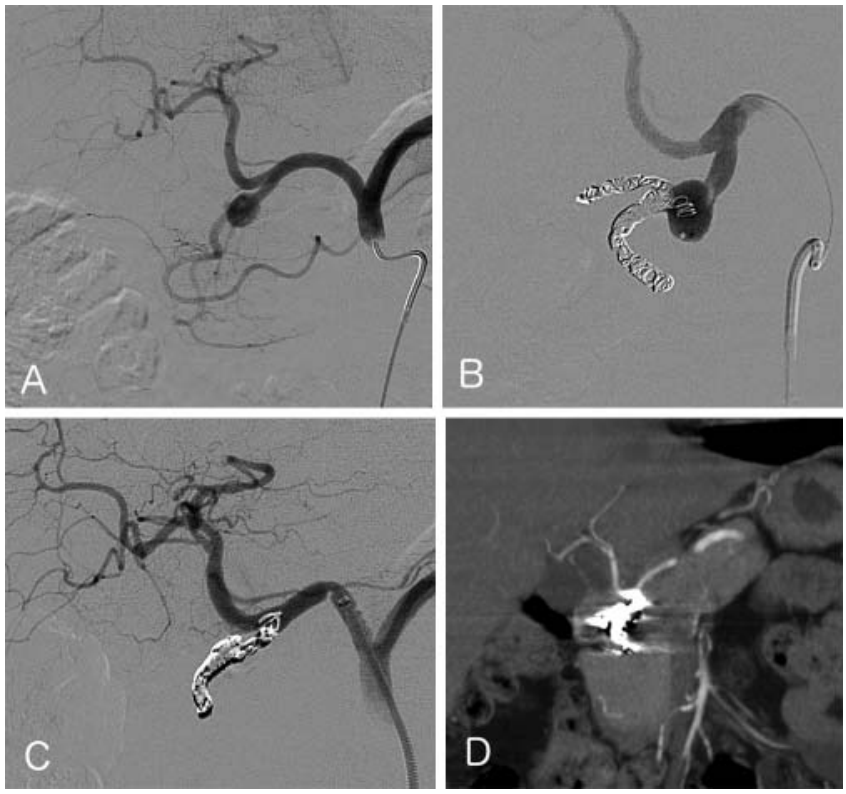

- Fig. 3 Treatment of a gastroduodenal artery aneurysm by coiling. A DSA of an incidental gastroduodenal artery aneurysm in a 54-year-old female patient. Contrast agent was administered via an SOS Omni catheter within the celiac trunk. B Successive coiling of two branches of the gastroduodenal artery for separating the aneurysm over a coaxially advanced microcatheter system. C Final inspection by celiac arteriography after coiling of the proximal gastroduodenal artery to eliminate the arterial supply. Partial dislocation of a coil into the hepatic artery is seen without any hemodynamic reduction in arterial blood flow. D Even in a follow-up CT examination 4 months later, perfusion of the hepatic artery was unaffected.

The characteristics of the treated patients and the aneurysms, technical aspects of the interventions and clinical aspects, such as technical treatment success and complications, were examined.

Visceral aneurysms are a rare entity even in a maximum care hospital with a large catchment area of approx. 2 million people. The etiology of the majority of aneurysms in the treated group and in comparison to other studies is vascular wall degeneration caused by atherosclerotic changes followed by pseudoaneurysm due to iatrogenic and inflammatory complications [4]. The number of iatrogenic changes, particularly the formation of pseudoaneurysms in the hepatic artery, has increased due to the growing number of percutaneous liver interventions, such as drain placement, biopsies, and PTCD (percutaneous transhepatic cholangiodrainage), and hepatobiliary surgery [5]. The five treated hepatic artery aneurysms in the patient population included two iatrogenic aneurysms: one occurring after a Whipple procedure and one after a gastrectomy.

Since patients to be treated are often at an increased operative risk due to additional comorbidities, endovascular intervention represents a safe and effective alternative to surgery. The indication for treatment is derived from the existing symptoms or is determined based on the rupture risk that increases with the diameter of the aneurysmal sac starting at a minimum size of $20 \mathrm{~mm}$ regardless of the diameter of the parent vessel [6]. In the examined 
- Table 4 The materials used depending on the location of the aneurysms.

\begin{tabular}{|l|l|l|l|l|l|}
\hline & \multicolumn{3}{|c|}{ type of material used: Absolute frequency and percentage in relation to the treated vascular territory } \\
\hline location & coils & $\begin{array}{l}\text { stent } \\
\text { graft }\end{array}$ & $\begin{array}{l}\text { liquid embolic } \\
\text { agent }\end{array}$ & $\begin{array}{l}\text { coils and } \\
\text { stent } \\
\text { graft }\end{array}$ & $\begin{array}{l}\text { coils and } \\
\text { liquid embolic } \\
\text { agent }\end{array}$ \\
plug and \\
plug
\end{tabular}

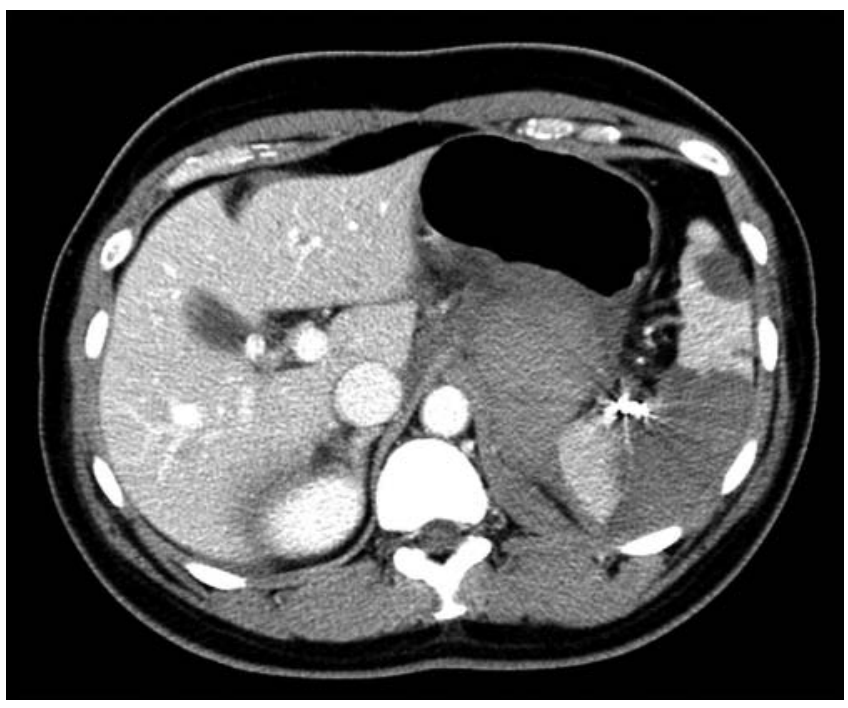

- Fig. 4 Splenic infarction after coiling of a splenic artery aneurysm. Contrast-enhanced CT of the upper abdomen in the portal venous phase one day after coiling of a bleeding splenic artery aneurysm. Examination was performed in a symptom-free patient for the evaluation of treatment success. It shows extended loss of arterial perfusion in the parenchyma distal to the coiled artery consistent with partial splenic infarction.

patient population, this size-dependent determination of an indication for treatment was expanded to include aneurysms with a diameter of less than $20 \mathrm{~mm}$ in the case of a clear request for treatment even in incidental asymptomatic aneurysms after the risks, alternatives, and common complications of the intervention were thoroughly explained to the patient. It must be taken into consideration that the natural course of small aneurysms (diameter of $<2 \mathrm{~cm}$ ) is not sufficiently described in the literature. However, the risk of rupture depends not only on the size but also on the location of the aneurysm. Therefore, hepatic artery aneurysms have a greater risk of rupture than splenic artery aneurysms [7]. 6 of the 15 asymptomatic true aneurysms had a diameter of less than $20 \mathrm{~mm}$. The indication to treat has been expanded to include asymptomatic aneurysms regardless of size in affected women who wish to become pregnant [8]. In addition, all sympto-
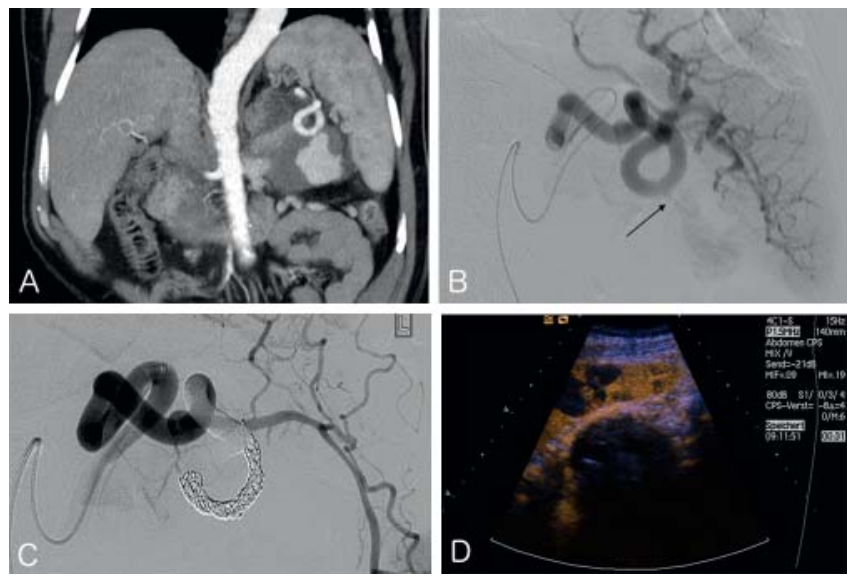

- Fig. 5 Postinterventional success control using contrast-enhanced ultrasound. A CT examination of an inflammatory splenic artery pseudoaneurysm on basis of chronic pancreatitis. Coronal MIPs show a large pseudocyst leading to an arrosion hemorrhage. B Selective angiography of the pseudoaneurysm. Arrow shows the faint contrast agent inflow in the pseudoaneurysm. C Final control after coiling of a long segment of the splenic artery with 15 coils shows successful occlusion of the injured vessel section. D Postinterventional contrast-enhanced ultrasound examination shows complete elimination of the aneurysm (by using 15 coils and an $8 \mathrm{~mm}$ vascular plug). No evidence of persistent perfusion. Furthermore, there is a partial perfusion loss of the nearby splenic parenchyma, which wasn't seen in the B-mode ultrasound examination.

matic aneurysms in patients with vasculitis should be treated immediately, while incidental aneurysms in such patients should be treated during an inflammation-free interval if they do not significantly reduce in size under immunosuppressive therapy [9]. In addition, all aneurysms with an increase in size of more than $0.5 \mathrm{~cm} /$ year should be treated [10].

A high technical success rate was seen. Among the 48 interventions, there was only one definitive case of treatment failure with a subsequent need for surgery. Five patients required a second intervention. Rates comparable to our primary technical success rate of $85 \%$ have also been seen in other studies (75$98 \%$ ) [11 - 13]. The re-intervention rates in the case of relapse 
or only partial primary success of $12.5 \%$ in this study are not significantly greater than the results of other studies with re-intervention rates of $3-11 \%[12-14]$ and comparable results of surgical therapy with re-operation rates of $0-12 \%[13,15,16]$. The mortality rate of the elective surgical therapy of visceral aneurysms is approximately $5 \%[15,17]$. Surgical therapy of actively bleeding aneurysms has a significantly higher mortality rate of $10-25 \%[18,19]$. In contrast, the mortality rate is $0 \%$ in our own study population and comparable results were seen in other studies $(3-7 \%)[8,13,20]$. However, some studies have shown that emergency interventional therapy has a significantly higher mortality rate of up to $17 \%$ compared to elective therapy [21]. This result was not confirmed in our own study population. Emergency treatment did not result in a significantly higher mortality rate. The periprocedural morbidity in the treated patient population is also low. The most common complication was post-interventional splenic infarction after the treatment of splenic aneurysms with a rate of $57 \%$ (4/7 patients in follow-up), 3 of which were symptomatic. This rate is higher than reported in other studies $(21-40 \%)[12,22]$. However, in the case of morbidity as well as mortality, the limited comparability due to differences in the classification of complications and the low number of cases both in the present study and in previous publications must be taken into consideration. The intervention-based total morbidity rate of $10 \%$ ( $8 \%$ requiring treatment) for all interventions of the examined population showed good comparability with other studies $(3-8 \%)[8,22,23]$. The perioperative morbidity of conventional surgical therapy in terms of surgery-associated complications in a period of up to 30 days after the operation of $7-13 \%$ is also comparable [15, 24, 25]. The study by Hemp and Sabri showed that there is no significant difference between endovascular and surgical therapy regarding periprocedural morbidity and mortality but that there was a significant reduction in the length of the hospital stay after interventional therapy [10].

Post-interventional control of the local finding via cross-sectional imaging is recommended at least in the immediate postinterventional period independent of the clinical course in order to rule out early reperfusion of the treated aneurysm or to detect complications requiring monitoring, such as parenchymal infarction of distal organs. Clearly defined follow-up strategies have not been established. At least one control immediately after the intervention during the hospital stay and one control after 3 and 12 months are typically performed particularly in the case of true aneurysms. However, the highly radiopaque coil material used in the majority of interventions often results, particularly in the case of $\mathrm{CT}$, in significant artifacts that greatly limit the ability to evaluate aneurysm perfusion and size. In regions that can be effectively viewed with ultrasound, e.g. in the region of the hilum of the spleen or the renal parenchyma, contrast-enhanced ultrasound can be a suitable means for post-interventional follow-up particularly given the lack of radiation exposure [26]. MRA is also highly sensitive with respect to the evaluation of the reperfusion of coiled aneurysms and can be used for long-term follow-up due to the lack of radiation exposure [27].

Interventional endovascular therapy of visceral artery aneurysms is a safe and technically successful treatment option. The treatment success is independent of the vascular territory and etiology. The size of the aneurysm is not a limiting factor. Thus, given comparable success and morbidity rates compared to convention surgery, intervention should be given preference particularly in patients with multiple comorbidities even in the emergency situation at centers with experienced interventional radiologists. In the case of a risk of reperfusion, follow-up for at least 1 year after treatment is recommended.

\section{Conclusion}

Interventional endovascular therapy of visceral artery aneurysms is a safe and effective treatment method both in elective and emergency situations. This applies to true aneurysms as well as pseudoaneurysms, which bleed significantly more often. Treatment success and periprocedural morbidity are independent of aneurysm size, location, and etiology. Given comparable periprocedural morbidity and mortality rates, multimorbid patients can benefit from the short duration of inpatient care required for the minimally invasive procedure. Given the risk of reperfusion after interventional therapy, follow-up for at least 1 year after treatment is recommended.

\section{CLINICAL RELEVANCE OF THE STUDY}

- Interventional endovascular therapy of visceral aneurysms is a safe and effective treatment especially for multimorbid patients even in the emergency situation.

- Due to the high risk of bleeding, there is an indication to treat all pseudoaneurysms.

- In the case of a risk of reperfusion following interventional therapy, follow-up is recommended even for incidental aneurysms possibly using MRI or CEUS to reduce the radiation exposure for the patient.

\section{Conflict of Interest}

The authors declare that they have no conflict of interest.

\section{References}

[1] Panayiotopoulos YP, Assadourian R, Taylor PR. Aneurysms of the visceral and renal arteries. Ann R Coll Surg Engl 1996; 78: 412-419

[2] Nosher JL, Chung J, Brevetti LS et al. Visceral and renal artery aneurysms: a pictorial essay on endovascular therapy. Radiographics 2006; 26: 1687 -1704; quiz 1687

[3] Omary RA, Bettmann MA, Cardella JF et al. Quality improvement guidelines for the reporting and archiving of interventional radiology procedures. J Vasc Interv Radiol 2003; 14: S293 - S295

[4] Pitton MB, Dappa E, Jungmann F et al. Visceral artery aneurysms: Incidence, management, and outcome analysis in a tertiary care center over one decade. Eur Radiol 2015; 25: 2004-2014

[5] Tessier D], Fowl RJ, Stone WM et al. latrogenic hepatic artery pseudoaneurysms: an uncommon complication after hepatic, biliary, and pancreatic procedures. Ann Vasc Surg 2003; 17: 663-669 
[6] Belli AM, Markose G, Morgan R. The role of interventional radiology in the management of abdominal visceral artery aneurysms. Cardiovasc Intervent Radiol 2012; 35: 234-243

[7] Cordova AC, Sumpio BE. Visceral artery aneurysms and pseudoaneurysms - should they all be managed by endovascular techniques? Ann Vasc Dis 2013; 6: 687-693

[8] Carroccio A, Jacobs TS, Faries P et al. Endovascular treatment of visceral artery aneurysms. Vasc Endovascular Surg 2007; 41: 373 - 382

[9] Tarhan NC, Coskun M, Kayahan EM et al. Regression of abdominal visceral aneurysms in polyarteritis nodosa: CT findings. Am J Roentgenol 2003; 180: 1617 - 1619

[10] Hemp JH, Sabri SS. Endovascular management of visceral arterial aneurysms. Tech Vasc Interv Radiol 2015; 18: 14-23

[11] Kasirajan K, Greenberg RK, Clair D et al. Endovascular management of visceral artery aneurysm. J Endovasc Ther 2001; 8: 150-155

[12] Tulsyan N, Kashyap VS, Greenberg RK et al. The endovascular manage ment of visceral artery aneurysms and pseudoaneurysms. J Vasc Surg 2007; 45: 276 - 283; discussion 283

[13] Cochennec F, Riga CV, Allaire E et al. Contemporary management of splanchnic and renal artery aneurysms: results of endovascular compared with open surgery from two European vascular centers. Eur J Vasc Endovasc Surg 2011; 42: 340 - 346

[14] Fankhauser GT, Stone WM, Naidu SG et al. The minimally invasive management of visceral artery aneurysms and pseudoaneurysms. J Vasc Surg 2011; 53: 966 - 970

[15] Chiesa R, Astore D, Guzzo G et al. Visceral artery aneurysms. Ann Vasc Surg 2005; 19: $42-48$

[16] Pulli R, Dorigo W, Troisi N et al. Surgical treatment of visceral artery aneurysms: A 25-year experience. J Vasc Surg 2008; 48: 334 - 342
[17] Messina LM, Shanley C]. Visceral artery aneurysms. Surg Clin North Am 1997; 77: $425-442$

[18] Mattar SG, Lumsden AB. The management of splenic artery aneurysms: experience with 23 cases. Am J Surg 1995; 169: 580 - 584

[19] Wagner WH, Allins AD, Treiman RL et al. Ruptured visceral artery aneurysms. Ann Vasc Surg 1997; 11: $342-347$

[20] Gabelmann A, Gorich J, Merkle EM. Endovascular treatment of visceral artery aneurysms. J Endovasc Ther 2002; 9: 38-47

[21] Roberts KJ, McCulloch N, Forde C et al. Emergency treatment of haemorrhaging coeliac or mesenteric artery aneurysms and pseudoaneurysms in the era of endovascular management. Eur J Vasc Endovasc Surg 2015; 49: 382 - 389

[22] Etezadi V, Gandhi RT, Benenati JF et al. Endovascular treatment of visceral and renal artery aneurysms. J Vasc Interv Radiol 2011; 22: 1246 1253

[23] Dorigo W, Pulli R, Azas L et al. Early and Intermediate Results of Elective Endovascular Treatment of True Visceral Artery Aneurysms. Ann Vasc Surg 2016; 30: $211-218$

[24] Marone EM, Mascia D, Kahlberg A et al. Is open repair still the gold standard in visceral artery aneurysm management? Ann Vasc Surg 2011; 25: $936-946$

[25] Corey MR, Ergul EA, Cambria RP et al. The natural history of splanchnic artery aneurysms and outcomes after operative intervention. J Vasc Surg 2016; 63: $949-957$

[26] Martegani A, Aiani L, Borghi C. Clinical Application of Contrast Ultrasound in Vascular Deseases. In: Lencioni R, Hrsg Enhancing the Role of Ultrasound with Contrast Agents. Berlin: Springer Verlag; 2006: 157 161

[27] Chiaradia M, Novelli L, Deux JF et al. Ruptured visceral artery aneurysms. Diagn Interv Imaging 2015; 96: 797 - 806 